\title{
Lanreotide extended-release aqueous-gel formulation, injected by patient, partner or healthcare provider in patients with acromegaly in the United States: 1-year data from the SODA registry
}

\author{
Roberto Salvatori • Whitney W. Woodmansee • \\ Mark Molitch • Murray B. Gordon • \\ Kathleen G. Lomax \\ Published online: 13 January 2013 \\ (c) The Author(s) 2013. This article is published with open access at Springerlink.com
}

\begin{abstract}
Lanreotide depot (LD; commercial name Somatuline ${ }^{\circledR}$ Depot) is an injectable, extended-release formulation of the synthetic somatostatin analog (SSA) lanreotide. In recent clinical trials, LD was found to be suitable for self or partner administration, avoiding the need to travel to a medical facility. The Somatuline ${ }^{\circledR}$ Depot for Acromegaly (SODA) study is an ongoing, multicenter, observational study in the US investigating the efficacy, safety, convenience and symptom relief provided by LD in patients with acromegaly. Sub-analyses explore outcomes according to who administered the injection: patient, partner, healthcare provider (HCP) or a combination. Data reported here reflect one year of patient experience. Patients are eligible for inclusion if they have a diagnosis of acromegaly, are treated with LD and can give signed
\end{abstract}

R. Salvatori $(\bowtie)$

Division of Endocrinology, Johns Hopkins University,

1830 East Monument Street \#333, Baltimore, MD 21287, USA

e-mail: salvator@jhmi.edu

W. W. Woodmansee

Division of Endocrinology, Diabetes and Hypertension,

Brigham and Women's Hospital/Harvard Medical School,

Boston, MA, USA

M. Molitch

Division of Endocrinology, Metabolism and Molecular

Medicine, Northwestern University Feinberg School

of Medicine, Chicago, IL, USA

M. B. Gordon

Allegheny Neuroendocrinology Center, Division

of Endocrinology, Allegheny General Hospital,

Pittsburgh, PA, USA

K. G. Lomax

Medical Affairs Endocrinology, Ipsen Biopharmaceuticals, Inc, Basking Ridge, NJ, USA informed consent. Baseline data include patient demographics, previous acromegaly treatment and investigations, GH and IGF-I levels, LD dose and dose adjustment frequency. Symptom frequency, injection pain and treatment convenience are assessed using patient-reported questionnaires. As of 18 April 2012, 166 patients had enrolled in SODA. Most (72\%) achieved normal IGF-I levels after 12 months of LD treatment. Disease control was similar in self or partner injectors and in patients who received injections from their $\mathrm{HCP}$, although self or partner injecting was deemed more convenient. LD was well-tolerated irrespective of who performed the injection. Self injection led to more injection-site reactions, but this did not increase the rate of treatment interruption. Acromegaly symptoms remained stable. Biochemical, safety and convenience data support the clinical validity of injecting $L D$ at home.

Keywords Acromegaly - Lanreotide depot - Extendedrelease $\cdot$ Observational study

\section{Introduction}

Acromegaly is a rare disorder that results from excessive production of growth hormone $(\mathrm{GH})$, usually due to a benign pituitary adenoma. Affecting approximately 40-125 people per million in the United States (US) [1], and possibly more [2-4], acromegaly is characterized by symptoms related to multiple body systems and increased risk of all-cause mortality [5]. Treatment typically entails surgical excision of the pituitary adenoma to normalize GH secretion, and to relieve compression symptoms in cases of larger tumor mass. However, complete tumor removal may not be possible if, as often happens, adenomas are large at 
the time of diagnosis, or in occasional cases when surgery is contraindicated or declined. As a result, over $50 \%$ of patients have active residual disease, defined by increased levels of GH, and/or its physiological mediator, insulin-like growth factor-1 (IGF-I), leading to persistent clinical symptoms, impaired health-related quality of life and increased mortality [6-8]. A recent systematic review of the literature determined that mortality, morbidity and cost are all higher in patients with biochemically uncontrolled acromegaly than in those with GH levels $<2.5 \mu \mathrm{g} / \mathrm{L}$ and IGF-I normal for age and gender [9]. As such, patients with uncontrolled disease typically receive pharmacological therapy such as somatostatin analogs (SSAs), the GH receptor antagonist pegvisomant or, less commonly, dopamine agonists or radiotherapy, to further reduce the symptoms and long-term consequences of unregulated GH secretion $[1,10]$.

Lanreotide depot (LD) is a synthetic octapeptide SSA that binds to somatostatin receptors Type 2 and - to a lesser degree-Type 5, inhibiting GH secretion and reducing IGF-I levels [11]. The long-acting, extended-release aqueous-gel formulation lanreotide depot is known in the US as Somatuline ${ }^{\circledR}$ Depot [12], and as Somatuline Auto$\mathrm{gel}^{\circledR}$ in the rest of the world. LD is approved in the US for the long-term treatment of acromegaly in patients with inadequate response, or contraindications, to surgery or radiotherapy [12]. LD is supplied as a pre-filled syringe for deep subcutaneous injection of 60,90 or $120 \mathrm{mg}$, does not require reconstitution, and was recently demonstrated in a 6-month clinical trial to be suitable for self or partner administration thus avoiding travel to a medical facility [13]. Whether LD may reliably be self-administered in the real-world setting remains unknown.

The Somatuline ${ }^{\circledR}$ Depot for Acromegaly (SODA) study is an ongoing, multicenter, observational study in the US, investigating the efficacy, safety, treatment convenience and symptom relief provided by LD in patients with acromegaly. Several post hoc sub-analyses have been conducted, including differences in outcome based on who administered the injection: patient, partner, healthcare provider (HCP) or a combination of injectors. The data reported in this manuscript reflect 1 year of patient experience in this ongoing study.

\section{Patients and methods}

\section{Patients}

Patients are eligible for inclusion in the SODA study if they have a clinical diagnosis of acromegaly, are treated with LD (including patients for whom LD is newly prescribed and those switched from other agents) and are competent to give signed informed consent. Those with symptomatic, untreated gallstones or known sensitivity to SSAs are ineligible. There is no limit on time from prior surgery or radiation therapy and patients can be enrolled at any time after starting the drug. Patients who have never received any form of octreotide and those who start LD within 30 days prior to enrollment are considered treatment-naïve. All eligible patients are included in the study and continue to receive $\mathrm{LD}$ as prescribed by their physician for the duration of their participation. The day on which the consent form is signed is considered the enrollment date.

\section{Study design and assessments}

The SODA study is carried out in academic and private treatment centers in the US. Baseline characteristics include patient demographics, previous acromegaly treatment and investigations, and hormone levels (GH and IGFI). LD dose and frequency of dose adjustment are recorded at every study visit after enrollment. As this is a noninterventional, observational study, the frequency of study visits, biochemical testing, radiological, echographic and sonographic evaluation is determined by the treating physician, and thus not all data points are available for all patients. Efficacy is assessed using serum IGF-I and GH concentrations evaluated at either a central or local laboratory with the recommended time points being at 3 and 6 months, then yearly. Investigators record whether the levels are normal, elevated or low for their particular hormone assay. Additional secondary analyses include safety, symptom burden and treatment convenience. Safety is evaluated by physical examination and recording of adverse events (AEs), which are categorized in the protocol as targeted (known to be associated with LD and other SSAs, such as injection site reactions, bradycardia, diarrhea, or cholelithiasis) or unexpected. Symptom burden (frequency), injection pain and treatment convenience are assessed by administering the two patient-reported questionnaires to each patient. The symptom questionnaire asks patients whether they experience specific symptoms always/most of the time/sometimes/rarely/never; it is recommended to be administered at enrollment, 6, 12 and 24 months after enrollment, and every subsequent 6 months until study completion, or at interval visits if these occur outside of the planned schedule. The convenience questionnaire inquires about who administers SSA injections, how long injections take to administer (including travel time to reach the clinic, if necessary) and whether injections are convenient, painful and/or technically difficult. It follows the same schedule as the symptom questionnaire except that the first post-enrollment questionnaire is administered at 12 months. Questionnaires are available in "Appendix". 
For this report, biochemical control (GH and IGF-I levels) was analyzed using the 1-year completer population, defined as all patients with IGF-I levels available at enrollment and month $12(\mathrm{n}=87)$. LD dose, symptom control, pain and convenience were analyzed for all patients who had the respective data available at enrollment and after one year; as such, the observed data reflect different patient numbers in each group. Safety analyses were conducted on all enrolled patients $(n=166)$. Data were categorized according to who administered the LD injections: patient, partner, HCP or any combination of patient, partner and HCP (the 'Combination/other' injector group). Statistical analyses were primarily descriptive. Data reported in this paper reflect a data cut on 18 April 2012.

\section{Results}

\section{Patients}

As of 18 April 2012, 166 patients had enrolled in SODA, $104(63 \%)$ from academic medical centers, and 62 (37\%) from private practice sites, across 22 states. Baseline characteristics of the enrolled population are presented in Table 1 . Acromegaly was caused by a pituitary adenoma in almost all patients (98\%). The majority $(80 \%)$ had undergone pituitary surgery, $20 \%$ had received radiation therapy and 123 subjects $(74 \%)$ had received previous pharmacological treatment in the form of SSAs, pegvisomant or a dopamine agonist; 19 (11\%) had not received any previous acromegaly treatment or had started LD $\leq 30$ days prior to enrollment (collectively considered treatment-naïve for this analysis).

IGF-I levels were elevated in half of the population (76/ 153 ) at enrollment and $28 \%$ (24/87) of 1-year completers. The proportion of samples analyzed at local laboratories was $80 \%$ at enrollment and $73 \%$ at 12 months; the remaining samples were analyzed at a central laboratory. The majority of patients were taking $90 \mathrm{mg}$ LD (Table 2). Almost all enrolled patients $(95 \%)$ received LD injections every 28 days and one was receiving $120 \mathrm{mg}$ at the extended dosing interval of every 42 days or longer. More patients received injections from their $\operatorname{HCP}(58 / 166 ; 35 \%)$ than from other sources; $16 \%$ self-injected, and the remaining $50 \%$ were evenly split between those who had injections administered by their partner and those who used a combination of methods.

Thirty-three patients discontinued the study during the first year, six due to personal choice, three for financial reasons, two died (one congestive heart failure and one cardiac arrest) and another 14 discontinued for other reasons (including pregnancy, change of physician, normal lab tests or breach of protocol). Eight were lost to follow-up.
Differences in discontinuation rates between injector subgroups were not significant.

\section{Biochemical control: IGF-I and GH levels}

In the 1-year completer population $(\mathrm{n}=87)$, the majority $(63 / 87 ; 72 \%)$ demonstrated biochemical control after 12 months, as evidenced by IGF-I levels below the upper limit of normal (Fig. 1); there was no significant difference between previously treated and treatment-naïve patients. IGF-I levels were normalized in a similar percentage of self $(13 / 15 ; 87 \%)$ and partner injectors $(16 / 18 ; 89 \%)$ and a somewhat lower proportion of subjects who received injections from their HCP $(18 / 27 ; 67 \%)$ or a combination of injectors $(16 / 27 ; 59 \%)(p=0.05$ between partnerinjectors and the combination/other group; all other pairwise comparisons were non-significant) (Fig. 1). However, when both groups of 'home injectors' (self and partner injectors) were compared with both groups of 'office injectors' (HCP and combination/other groups), a significantly greater proportion of home injectors had normalized IGF-I levels after 12 months [29/33 (88 \%) vs. 34/54 (63\%); $p=0.01$ on Fisher's Exact test]. Mean fasting $\mathrm{GH}$ level after 12 months, based on data available in 50 patients, was $1.7 \pm 2.2 \mathrm{ng} / \mathrm{mL}$; levels were $\leq 2.5 \mathrm{ng} / \mathrm{mL}$ in $40 / 50(80 \%)$ patients and $<1 \mathrm{ng} / \mathrm{mL}$ in $30 / 50(60 \%)$ patients.

\section{Lanreotide depot dosing}

LD dose information was available for 146 patients at 12 months (Table 2). In total, 42 (29\%) had dose adjustments in the first year of enrollment in the study. The proportion of subjects taking a $90 \mathrm{mg}$ dose decreased in the first year while the proportion taking $120 \mathrm{mg}$ increased, representing a general trend towards dose increase. Dose adjustment was most commonly prompted by elevated IGF-I levels (24/42; $57 \% ; p=$ NS between groups); other reasons included low IGF-I levels $(9 / 42 ; 21 \%)$, high $\mathrm{GH}$ levels $(7 / 42 ; 17 \%)$ and other reasons $(10 / 42 ; 24 \%)$. As at enrollment, the majority ( $89 \%$ ) were administering injections every 28 days after 12 months of treatment.

\section{Symptoms and convenience}

A total of 100 patients (100/166; $60 \%)$ completed the symptom questionnaire both at enrollment and 12 months. At enrollment, tiredness was the most common symptom (72/100; $72 \%)$ followed by snoring $(68 / 100 ; 68 \%)$, pain $(64 / 100 ; 64 \%)$, sweating $(58 / 100 ; 58 \%)$, and headache $(32 / 100 ; 32 \%)$. After 12 months, all symptoms remained stable in these 100 patients. 
Table 1 Baseline characteristics of 166 patients at time of enrollment in SODA Study

\begin{tabular}{|c|c|c|c|c|c|}
\hline & \multicolumn{4}{|c|}{ Injection administered by } & \multirow[b]{2}{*}{$\begin{array}{l}\text { All patients } \\
(\mathrm{n}=166)\end{array}$} \\
\hline & $\begin{array}{l}\text { Patient always } \\
(\mathrm{n}=26)\end{array}$ & $\begin{array}{l}\text { Partner always } \\
(\mathrm{n}=41)\end{array}$ & $\begin{array}{l}\text { HCP always } \\
(\mathrm{n}=58)\end{array}$ & $\begin{array}{l}\text { Combination/other } \\
(\mathrm{n}=41)\end{array}$ & \\
\hline Gender, \% M/F & $35 / 65$ & $59 / 42$ & $43 / 57$ & $66 / 34$ & $51 / 49$ \\
\hline Mean age, years (range) & $52 \pm 12(23-73)$ & $52 \pm 16(22-84)$ & $49 \pm 17(13-86)$ & $49 \pm 13(25-73)$ & $50 \pm 15(13-86)$ \\
\hline Time since diagnosis, months (mean) & $99 \pm 77$ & $65 \pm 63$ & $98 \pm 117$ & $96 \pm 105$ & $89 \pm 98$ \\
\hline \multicolumn{6}{|l|}{ Etiology of acromegaly, $\mathrm{n}(\%)^{\mathrm{a}}$} \\
\hline Pituitary adenoma & $26(100)$ & $41(100)$ & $56(97)$ & $40(98)$ & $163(98)$ \\
\hline McCune-Albright syndrome & 0 & $1(2)$ & $1(2)$ & 0 & $2(1)$ \\
\hline Other $^{\mathrm{b}}$ & 0 & 0 & $1(2)$ & $1(2)$ & $2(1)$ \\
\hline IGF-I level measured $^{\mathrm{c}}(\mathrm{n})$ & 25 & 36 & 52 & 40 & 153 \\
\hline High, n (\%) & $10(40)$ & $15(42)$ & $28(54)$ & $23(58)$ & $76(50)$ \\
\hline Normal, n (\%) & $14(56)$ & $21(58)$ & $23(44)$ & $16(40)$ & $74(48)$ \\
\hline Low, n (\%) & $1(4)$ & 0 & $1(2)$ & $1(3)$ & $3(2)$ \\
\hline Unknown, n (\%) & $1(4)$ & $5(12)$ & $6(15)$ & $1(3)$ & $13(8)$ \\
\hline Peak glucose-suppression GH level (n) & 6 & 4 & 6 & 8 & 24 \\
\hline Median, ng/mL & 1.1 & 0.7 & 2.5 & 2.0 & 1.8 \\
\hline Trough $\mathrm{GH} \leq 2.5 \mathrm{ng} / \mathrm{mL}, \mathrm{n}(\%)$ & $5(83)$ & $3(75)$ & $3(50)$ & $5(63)$ & $16(67)$ \\
\hline Trough $\mathrm{GH} \leq 1 \mathrm{ng} / \mathrm{mL}, \mathrm{n}(\%)$ & $3(50)$ & $3(75)$ & $2(33)$ & $3(38)$ & $11(46)$ \\
\hline Prior pituitary surgery, n (\%) & $24(92)$ & $29(71)$ & $44(76)$ & $36(88)$ & $133(80)$ \\
\hline Prior radiation therapy, $\mathrm{n}(\%)$ & $2(8)$ & $5(12)$ & $15(26)$ & $12(29)$ & $34(20)$ \\
\hline Prior medical therapy, $\mathrm{n}(\%)^{\mathrm{d}, \mathrm{e}}$ & $20(77)$ & $28(68)$ & $45(78)$ & $30(73)$ & $123(74)$ \\
\hline SSA & $15(58)$ & $19(46)$ & $39(67)$ & $24(59)$ & $97(58)$ \\
\hline Short-acting octreotide & 0 & $1(2)$ & $12(21)$ & $2(5)$ & $15(9)$ \\
\hline Long-acting octreotide & $15(58)$ & $18(44)$ & $27(47)$ & $22(54)$ & $82(49)$ \\
\hline Dopamine agonist & $9(35)$ & $17(42)$ & $14(24)$ & $11(27)$ & $51(31)$ \\
\hline Pegvisomant & $5(19)$ & $2(5)$ & $12(21)$ & $9(22)$ & $28(17)$ \\
\hline None (treatment-naïve) & $2(8)$ & $7(17)$ & $5(9)$ & $5(12)$ & $19(11)$ \\
\hline
\end{tabular}

Given the non-interventional nature of the study, not all datapoints are available for all patients

GH growth hormone, GHRH growth-hormone releasing hormone, IGF-I insulin-like growth factor-1, SSA somatostatin analog

a Categories are not mutually exclusive; two subjects were categorized as having a GH-secreting macroadenoma and a pituitary adenoma; one subject had a pituitary adenoma and McCune-Albright syndrome

b Pituitary enlargement with high IGF-I, suggesting a probable GHRH-secreting pinealoma

c The proportion of IGF-I samples analyzed centrally was $20 \%$ at enrollment and $27 \%$ at 12 months; the remaining samples were analyzed in local institutional laboratories. Values determined to be high, normal or low by investigator

${ }^{d}$ Values based on case report forms which did not identify patients using lanreotide depot

e Therapies were not mutually exclusive

There was a second questionnaire concerning pain and convenience filled out by the patients. At enrollment, $33 \%$ (54/166) of the patients reported LD injections to be painless, $55 \%(92 / 166)$ described them as mildly/moderately painful and $11 \%$ (19/166) found injections very/extremely painful. Responses after 12 months of treatment with LD were similar to those at enrollment. Convenience data (Fig. 2) indicated that overall, for the 102 patients who completed this questionnaire at both enrollment and month 12, $72 \%$ (73/ 102) of patients found LD very or somewhat convenient, although HCP injection was considered less convenient than self or partner injection at enrollment and at 12 months.

\section{Adverse events}

In all, $61 \%(101 / 166)$ of patients reported at least one AE, with minimal difference between injector subgroups. The most common targeted AEs (occurring in $\geq 10 \%$ of patients) were arthralgia, headache and gastrointestinal disturbances (Table 3). Injection site reactions were considerably more common when patients injected themselves than when they were injected by someone else [19\% $(5 / 26)$ self injectors versus $2 \%$ (1/41) partner injectors; $p<0.05]$. Eleven percent of patients (18/166) reported a total of 41 serious AEs (SAEs). Cerebrovascular accident 
Table 2 Lanreotide depot dose (n, \%) at enrollment and after 12 months of treatment

\begin{tabular}{|c|c|c|c|c|c|}
\hline Dose at enrollment (mg) & $\begin{array}{l}\text { Patient always } \\
\mathrm{n}=26\end{array}$ & $\begin{array}{l}\text { Partner always } \\
\mathrm{n}=41\end{array}$ & $\begin{array}{l}\text { HCP always } \\
\mathrm{n}=58\end{array}$ & $\begin{array}{l}\text { Combination/other } \\
\mathrm{n}=41\end{array}$ & $\begin{array}{l}\text { All patients } \\
(\mathrm{n}=166)\end{array}$ \\
\hline 60 & $1(4)$ & $6(15)$ & $11(19)$ & $9(22)$ & $27(16)$ \\
\hline 90 & $18(69)$ & $24(59)$ & $29(50)$ & $23(56)$ & $94(57)$ \\
\hline 120 & $7(27)$ & $11(27)$ & $18(31)$ & $9(22)$ & $45(27)$ \\
\hline Dose at 12 months $(\mathrm{mg})$ & $\mathrm{n}=23$ & $\mathrm{n}=38$ & $\mathrm{n}=50$ & $\mathrm{n}=35$ & $\begin{array}{l}\text { All patients } \\
(\mathrm{n}=146)\end{array}$ \\
\hline 60 & $1(4)$ & $6(16)$ & 7 (14) & $7(20)$ & $21(14)$ \\
\hline 90 & $10(44)$ & $19(50)$ & $21(42)$ & $12(34)$ & $62(43)$ \\
\hline 120 & $12(53)$ & $13(34)$ & $22(44)$ & $15(43)$ & $62(43)$ \\
\hline
\end{tabular}

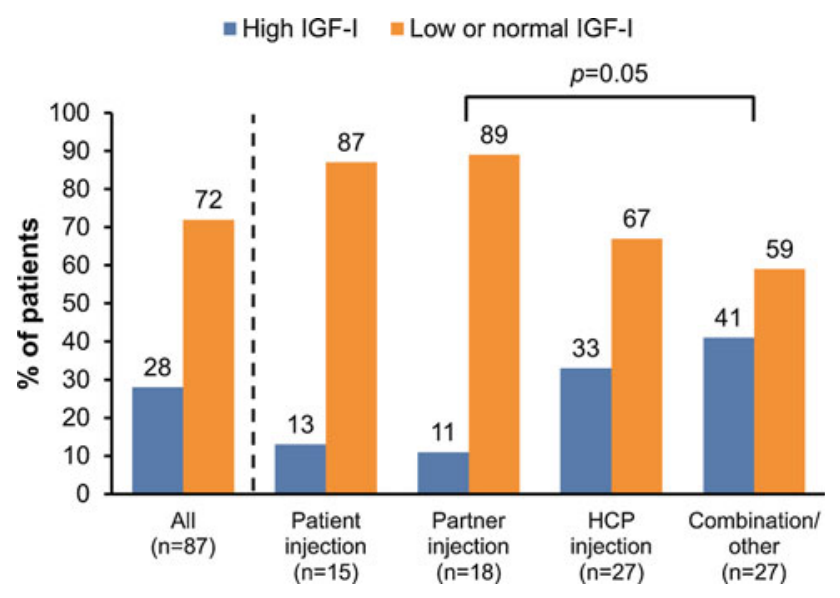

Fig. 1 IGF-I levels after 12 months' treatment with lanreotide depot $(\mathrm{n}=87)$. The 'Combination/other' group comprises patients who received injections from any combination of injectors [self, partner, $(\mathrm{HCP})]$

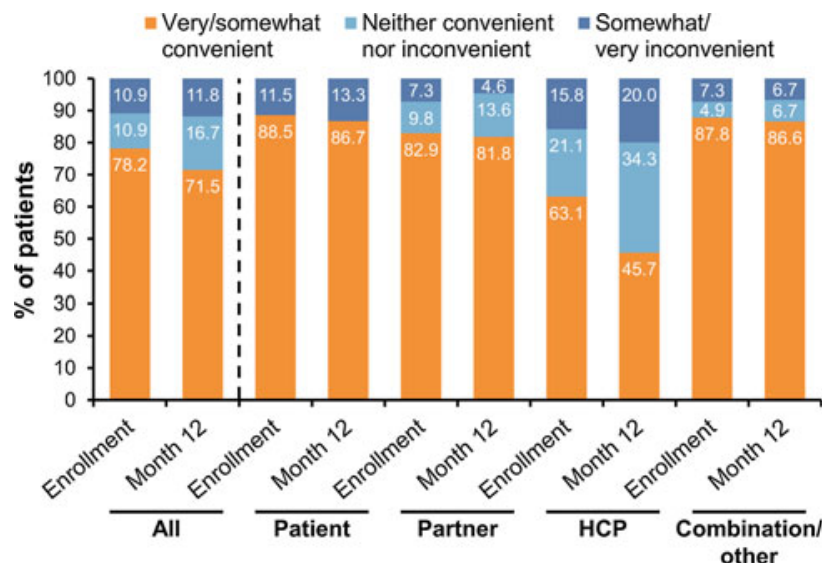

Fig. 2 Self-reported convenience of lanreotide depot according to who injected the treatment. The 'Combination/other' group comprises patients who received injections from any combination of injectors [self, partner, healthcare provider (HCP)] $(\mathrm{n}=3$ ) was the most common SAE, followed by pneumonia, acute renal failure, and urinary tract infection ( $n=2$ for each). In three patients, SAEs were considered possibly related to LD treatment (depression/suicidal ideation, atrial fibrillation, cluster headache). Both deaths were considered unrelated to treatment by the investigator.

\section{Discussion}

In this real-world, observational study in patients with active acromegaly treated with LD, alone or as combination therapy, most $(72 \%)$ patients achieved normal IGF-I levels after 1 year, indicating attainment of biochemical disease control. Approximately one-third of patients required LD dose adjustment during the year, typically an increase from 90 to $120 \mathrm{mg}$ due to persistently elevated IGF-I levels. The percentage of patients achieving biochemical control in this study is higher than has generally been reported previously with SSAs [14], and likely reflects an enrollment bias since subjects who were poorly or non-responsive to LD are less likely to be enrolled and/or to continue receiving LD in this real-life study. Our data were too few to allow comparison of response rates between treatment-naïve and previously treated subjects. More importantly, disease control was similar in those who self or partner injected when compared to patients who always received injections from their HCP. Furthermore, comparison of exclusively home injectors (patient or partner only) with patients who received office injections revealed that a significantly greater proportion of exclusively home injectors achieved biochemical control after 1 year of LD treatment, which may reflect a tendency of patients who respond better to visit the physician's office less often. In conjunction with stable symptoms, good tolerability, and data indicating that self and partner injecting were more convenient than injections administered by a HCP, these data support the clinical validity and lifestyle benefits of injecting $L D$ at home. The only $\mathrm{AE}$ that occurred with greater frequency among self 
Table 3 Targeted AEs reported by $\geq 10 \%$ of all patients

\begin{tabular}{llllll}
\hline & \multicolumn{2}{l}{ Injection administered by } & & \\
\cline { 2 - 5 } & $\begin{array}{l}\text { Patient } \\
(\mathrm{n}=26)\end{array}$ & $\begin{array}{l}\text { Partner } \\
(\mathrm{n}=41)\end{array}$ & $\begin{array}{l}\text { HCP } \\
(\mathrm{n}=58)\end{array}$ & $\begin{array}{l}\text { Combination/ } \\
\text { other }(\mathrm{n}=41)\end{array}$ & $\begin{array}{l}\text { All patients } \\
(\mathrm{n}=166)\end{array}$ \\
\hline $\begin{array}{l}\text { Number of patients with } \\
\geq 1 \text { targeted AE (n, \%) }\end{array}$ & $15(58)$ & $23(56)$ & $30(52)$ & $23(56)$ & $91(55)$ \\
$\begin{array}{l}\text { Targeted AEs } \\
\text { Arthralgia }\end{array}$ & $4(15)$ & $9(22)$ & $17(29)$ & $6(15)$ & $36(22)$ \\
Headache & $8(31)$ & $10(25)$ & $9(16)$ & $9(22)$ & $36(22)$ \\
Diarrhea & $1(4)$ & $12(29)$ & $8(14)$ & $11(27)$ & $32(19)$ \\
Abdominal pain & $2(8)$ & $10(24)$ & $10(17)$ & $9(22)$ & $31(19)$ \\
Nausea & 0 & $10(24)$ & $9(16)$ & $5(12)$ & $24(15)$ \\
Constipation & $3(12)$ & $4(10)$ & $8(14)$ & $7(17)$ & $22(13)$ \\
Flatulence & $2(8)$ & $7(17)$ & $4(7)$ & $8(20)$ & $21(13)$ \\
Injection site reaction & $5(19)$ & $1(2)$ & $4(7)$ & $3(7)$ & $13(8)$ \\
\hline
\end{tabular}

AEs adverse events, $H C P$ healthcare provider data, providing support for the validity of self or partner injecting in the real-world clinical environment.

The SODA study has a number of limitations. Firstly, it is an observational study and not a randomized controlled trial. As such, the causative role of LD on the reported outcomes is hard to determine or quantify. Secondly, an enrollment bias toward SSA-responsive patients is evident. Thirdly, the SODA population is highly heterogeneous due to enrollment at different stages of disease and treatment. Therefore, while the results provide a real-life snapshot of the SODA patient population at 1 year, the conclusions that can be drawn with respect to particular patient groups are limited. Finally, selection bias among treating physicians toward prescribing this medication for patients who are more likely to successfully self-administer the drug cannot be excluded. Such limitations notwithstanding, these 1-year data suggest that administration of LD at home by self or partner provides similar biochemical control to injections administered in the healthcare provider's office, with similar tolerability and greater convenience. Longer-term data and/or data from controlled trials will be necessary to corroborate these findings.

Acknowledgments The authors express their gratitude to all SODA patients, investigators, and study coordinators for their commitment to this observational study. The authors accept direct responsibility for this paper and are grateful for the contribution made by Esther Nathanson, MD at Watermeadow Medical USA (supported by Ipsen) in the development of the outline and first draft, and in collating comments for subsequent drafts. The authors are also thankful for the statistical support provided by Rongdean Chen, $\mathrm{PhD}$ and Weiyuan Chung, MS. This study was sponsored by Ipsen Biopharmaceuticals, Inc. (Basking Ridge, NJ, US).

Conflict of interest KGL is an employee of Ipsen Biopharmaceuticals, Inc. RS, WWW, MM and MG have served as advisory board members and received consulting fees from Ipsen Biopharmaceuticals, Inc.

Open Access This article is distributed under the terms of the Creative Commons Attribution License which permits any use, distribution, and reproduction in any medium, provided the original author(s) and the source are credited. 


\section{Appendix}

\section{CONVENIENCE QUESTIONNAIRE}

Did the patient receive the study enrollment visit injection at your office?

$\square$ Yes

$\square$ No

Please answer the following questions after administration of Somatuline Depot:

Who administered the injection?

$\square$ Health care provider

$\square$ Patient

D Partner

Who will be administering subsequent injections?

Endocrine office personnel

$\square$ Local health care provider

$\square$ Patient

$\square$ Partner

Did the patient find the Somatuline Depot injection to be:

$\square$ Not painful

$\square$ Somewhat painful

$\square$ Moderately painful

$\square$ Very painful

Extremely painful

Did the patient find the Somatuline Depot injection to be:

$\square$ Very convenient

$\square$ Somewhat convenient

$\square$ Neither convenient nor inconvenient

$\square$ Somewhat inconvenient

$\square$ Very inconvenient

Were there any difficulties during the administration of Somatuline Depot?

$\square$ Yes

$\square$ No

If yes, please check as many as apply:

Insertion of needle through the skin

Injecting Somatuline Depot after needle was inserted through the skin

Other

If other, please specify

CONVENIENCE QUESTIONNAIRE FOR PATIENTS PREVIOUSLY TREATED WITH LONG-ACTING SANDOSTATIN

Please answer the following questions about the patient's use of Long-Acting Sandostatin:

$\square$ Check if the patient has NOT been previously treated with Long-Acting Sandostatin:

I experienced Sandostatin LAR injections to be:

$\square$ Not painful

$\square$ Somewhat painful

Moderately painful

$\square$ Very painful

Extremely painful 


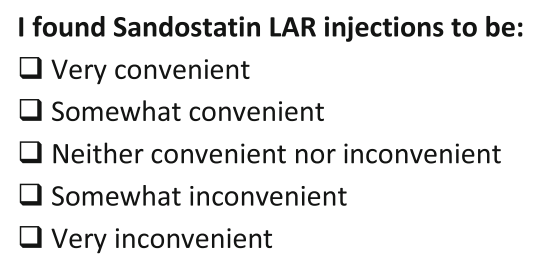

To receive one injection of Sandostatin LAR in the doctor's office, I had to travel (one way):

$\square$ Did not travel

$\square$ Less than 10 miles
$\square$ Between 10 and 40 miles
$\square$ Between 40 and 70 miles
$\square$ Between 70 and 100 miles
$\square$ More than 100 miles

Total time to receive one injection of Sandostatin LAR in the doctor's office including travel and office wait time:

$\square$ Did not travel

$\square$ Less than 1 hour

Between 1 and 3 hours

Between 3 and 5 hours

$\square$ Between 5 and 7 hours

More than 7 hours

\section{SYMPTOM QUESTIONNAIRE}

\begin{tabular}{|c|c|c|c|c|c|}
\hline \multicolumn{6}{|c|}{ SYMPTOM QUESTIONNAIRE } \\
\hline & Always & $\begin{array}{l}\text { Most of } \\
\text { the time }\end{array}$ & Sometimes & Rarely & Never \\
\hline 1. I sweat more than other people & $\bigcirc$ & $\bigcirc$ & $\mathrm{O}$ & $\mathrm{O}$ & $\mathrm{O}$ \\
\hline 2. I snore & O & $\mathrm{O}$ & $\mathrm{O}$ & $\mathrm{O}$ & O \\
\hline $\begin{array}{l}\text { 3. I have joint pains in my elbows, } \\
\text { knees and/or other body parts }\end{array}$ & O & O & $\mathrm{O}$ & O & $\bigcirc$ \\
\hline $\begin{array}{l}\text { 4. I have headaches that affect my } \\
\text { daily routine }\end{array}$ & O & $\mathrm{O}$ & $\mathrm{O}$ & $\mathrm{O}$ & $\mathrm{O}$ \\
\hline 5. I feel tired during the day & O & $\mathrm{O}$ & $\mathrm{O}$ & $\mathrm{O}$ & $\mathrm{O}$ \\
\hline
\end{tabular}

\section{References}

1. Katznelson L, Atkinson JL, Cook DM, Ezzat SZ, Hamrahian AH, Miller KK (2011) American Association of clinical Endocrinologists: American Association of Clinical Endocrinologists medical guidelines for clinical practice for the diagnosis and treatment of acromegaly-2011 update. Endocr Pract 17(Suppl 4): $1-44$

2. Rosario PW (2011) Frequency of acromegaly in adults with diabetes or glucose intolerance and estimated prevalence in the general population. Pituitary 14(3):217-221

3. Daly AF, Rixhon M, Adam C, Dempegioti A, Tichomirowa MA, Beckers A (2006) High prevalence of pituitary adenomas: a cross-sectional study in the province of Liege, Belgium. J Clin Endocrinol Metab 91(12):4769-4775

4. Schneider HJ, Sievers C, Saller B, Wittchen HU, Stalla GK (2008) High prevalence of biochemical acromegaly in primary care patients with elevated IGF-1 levels. Clin Endocrinol (Oxf) 69(3):432-435
5. Dekkers OM, Biermasz NR, Pereira AM, Romijn JA, Vandenbroucke JP (2008) Mortality in acromegaly: a metaanalysis. J Clin Endocrinol Metab 93(1):61-67

6. Melmed S (2006) Medical progress: acromegaly. N Engl J Med 355(24):2558-2573

7. Webb SM (2006) Quality of life in acromegaly. Neuroendocrinology 83(3-4):224-229

8. Cook DM, Ezzat S, Katznelson L, Kleinberg DL, Laws ER Jr, Nippoldt TB, Swearingen B, Vance ML (2004) American Association of Clinical Endocrinologists medical guidelines for clinical practice for the diagnosis and treatment of acromegaly. Endocr Pract 10:213-225

9. Ben-Shlomo A, Sheppard MC, Stephens JM, Pulgar S, Melmed S (2011) Clinical, quality of life, and economic value of acromegaly disease control. Pituitary 14(3):284-294

10. Giustina A, Bronstein MD, Casanueva FF, Chanson P, Ghigo E, Ho KK, Klibanski A, Lamberts S, Trainer P, Melmed S (2011) Current management practices for acromegaly: an international survey. Pituitary 14(2):125-133 
11. Andersen M (2007) The role of lanreotide Autogel ${ }^{\circledR}$ in the treatment of acromegaly. Expert Rev Endocrinol Metab 2(3):433-441

12. Somatuline Depot prescribing information (2012) Ipsen biopharmaceuticals. Inc. Basking Ridge, NJ

13. Salvatori R, Nachtigall LB, Cook DM, Bonert V, Molitch ME, Blethen S, Chang S (2010) SALSA study group: effectiveness of self or partner administration of an extended-release aqueous-gel formulation of lanreotide in lanreotide-naïve patients with acromegaly. Pituitary 13(2):115-122

14. Freda PU, Katznelson L, van der Lely AJ, Reyes CM, Zhao S, Rabinowitz D (2005) Long-acting somatostatin analog therapy of acromegaly: a meta-analysis. J Clin Endocrinol Metab 90(8): 4465-4473

15. Zwibel H, Pardo G, Smith S, Denney D, Oleen-Burkey M (2011) A multicenter study of the predictors of adherence to self-injected glatiramer acetate for treatment of relapsing-remitting multiple sclerosis. J Neurol 258(3):402-411
16. Cameron ST, Glasier A, Johnstone A (2012) Pilot study of home self-administration of subcutaneous depo-medroxyprogesterone acetate for contraception. Contraception 85(5):458-464

17. Bygum A, Andersen KE, Mikkelsen CS (2009) Self-administration of intravenous C1-inhibitor therapy for hereditary angioedema and associated quality of life benefits. Eur J Dermatol 19(2):147-151

18. Colwell CW Jr, Pulido P, Hardwick ME, Morris BA (2005) Patient compliance with outpatient prophylaxis: an observational study. Orthopedics 28(2):143-147

19. Bevan JS, Newell-Price J, Wass JA, Atkin SL, Bouloux PM, Chapman J, Davis JR, Howlett TA, Randeva HS, Stewart PM, Viswanath A (2008) Home administration of lanreotide Autogel by patients with acromegaly, or their partners, is safe and effective. Clin Endocrinol (Oxf) 68(3):343-349 